\title{
Upaya Penanaman Pendidikan Karakter di Sekolah Dasar Telaah Pendekatan Struktural Fungsional Talcott Parsons
}

\author{
Anjar Sulistiawati ${ }^{1}{ }^{\circledR}$ Khoirudin Nasution ${ }^{2}$
}

\author{
Pascasarjana PGMI, Universitas Islam Negeri Kalijaga, Indonesia \\ E-mail: anjarsulistiawati128@gmail.com
}

\begin{abstract}
Abstrak
Tujuan penelitian ini adalah untuk mengetahui upaya penanaman pendidikan karakter di sekolah dasar berdasarkan teori struktural fungsional Talcott Parsons. Pendekatan penelitian ini yaitu kualitatif deskriptif dengan metode observasi dan telaah literatur. Objek materil yaitu upaya penanaman pendidikan karakter di SD Negeri Trayu dengan objek formal pendekatan struktural fungsional Talcott Parsons. Analisis data yang digunakan adalah analisis sinkronisasi antara upaya penanaman pendidikan karakter dilapangan dengan teori struktural fungsional Talcott Parsons. Teori Talcott Parsons yaitu masyarakat sebagai suatu sistem saling berhubungan dan saling bergantung. Faktor terpenting dari suatu integrasi sistem sosial yaitu kesepakatan. Kemudian Talcott Parsons mengembangkan konsep imperatif fungsional untuk membuat sistem bertahan. Konsep imperatif ini biasanya disebut sebagai AGIL, yang merupakan singkatan dari Adaptation, Goal attainment, Integration, dan Latency. kesimpulannya bahwa penanaman pendidikan karakter di sekolah dalam hal ini dianalisis dengan pendekatan teori struktural fungsional Talcott Parsons melalui 4 tahap yaitu; tahap penetapan dengan tujuan penanaman pendidikan karakter goal attaintment, tahap adaptation sebagai proses adaptasi peserta didik dengan tata tertib dan kebiasaan di sekolah dalam rangka mencapai tujuan pendidikan karakter, tahap integration penanaman pendidikan karakter dapat diintegrasikan dengan kegiatan intrakurikuler, ko-kurikuler, dan ekstrakurikuler. Kemudian pada tahap latency strategi penanaman pendidikan karakter harus dilaksanakan secara terus menerus atau berkesinambungan.
\end{abstract}

Kata Kunci: Pendidikan Karakter; Sekolah Dasar; Struktural Fungsional; Talcott Parsons.

\begin{abstract}
The purpose of this study was to determine the efforts to inculcate character education in elementary schools based on Talcott Parsons' structural-functional theory. This research approach is descriptive qualitative with the method of observation and literature review. The material object is the effort to cultivate character education in SD Negeri Trayu with the object of a formal structural functional approach of Talcott Parsons. Analysis of the data used is an analysis of the relationship between efforts to cultivate character education in the field with Talcott Parsons' structural-functional theory. Talcott Parsons' theory is that society as a system is interconnected and interdependent. The most important factor of an integrated social system is agreement. Then Talcott Parsons developed the concept of functional imperatives to make systems last. This imperative concept is usually referred to as AGIL, which stands for Adaptation, Goal attainment, Integration, and Latency. The conclusion is that the cultivation of character education in schools in this case is analyzed by using the structural functional theory approach of Talcott Parsons through 4 stages, namely; the determination stage with the aim of planting character education to achieve goals, the adaptation stage as a process of adapting students to the rules and habits at school in order to achieve the goals of character education, the integration stage of character education planting can be integrated with intracurricular, co-curricular, and extracurricular activities. Then at the latency strategy stage, character education must be carried out continuously or continuously.
\end{abstract}

Keywords: Character building; Primary School; Structural Functional; Talcott Parsons. 


\section{PENDAHULUAN}

Pendidikan adalah kunci merupakan kunci dalam meningkatkan kualitas suatu bangsa. Bangsa yang maju selalu dimulai dari pendidikan yang maju karena pendidikan sebagai pengembangan kualitas dan kemampuan masyarakat. Dengan masyarakat yang terdidik dapat mewujudkan bangsa yang maju dan berpendidikan. Pendidikan yan tepat dapat mewujudkan citacita suatu bangsa dalam berbagai aspek kehidupan termasuk kedisiplinan, etos kerja, dan nilai moral suatu bangsa. Dalam rangka mewujudkan nilai-nilai tersebut, maka diperlukan manajemen pendidikan yang tidak hanya sebagai wadah mencerdaskan, tetapi juga sebagai wadah penanaman karakter anak.

Upaya penanaman pendidikan karakter melalui di Indonesia melalui gerakan Pengatan Pendidikan Karakter (PPK). Kemudian ditegaskan dengan gagasan Profil Pelajar Pancasila yang sesuai Visi dan Misi Kementerian Pendidikan dan Kebudayaan sebagaimana tertuang dalam dengan Peraturan Menteri Pendidikan dan Kebudayaan Nomor 22 Tahun 2020 tentang Rencana Strategis Kementerian Pendidikan dan Kebudayaan Tahun 2020-2024. Melalui PPK ini, karakter peserta didik dapat terbentuk lebih sempurna, diperkuat melalui harmonisasi hati (etika), olah rasa (estetika), olah pikir (literasi) dan olah raga (kinestetik); dengan dukungan pelibatan masyarakat dan kerjasama antara sekolah, keluarga dan masyarakat. Nilai-nilai karakter yang ditanamkan melalui gerakan PPK adalah nilai-nilai agama, nasionalisme, kemandirian, gotong royong dan integritas. Urgensi PPK ini adalah membangun Sumber Daya Manusia yang menjadi tumpuan pembangunan bangsa. Generasi yang harus dibangkitkan adalah Generasi Emas , memiliki kualitas karakter, literasi dasar dan keterampilan 4C (Critical thinking, Creativity, Communication, and Collaboration) (Anshori, 2017).

$$
\text { Pendidikan Karakter menjadi }
$$

keharusan karena pendidikan tidak hanya menjadikan peserta didik cerdas, pendidikan juga untuk membangun budi pekerti dan sopan santun dalam kehidupan (Rohendi, 2010). Karakter adalah hal penting yang harus dimiliki suatu bangsa untuk dapat eksis dalam persaingan global. Struktur masyarakat yang ada dalam suatu negara berfungsi untuk menjaga agar nilai-nilai karakter yang berlaku di masyarakat agar kehidupan masyarakat berjalan stabil dan keteraturan (Sidi, 2014). Pendidikan karakter mengajarkan kebiasaan cara berpikir dan perilaku yang membantu individu untuk hidup dan bekerja bersama sebagai keluarga, masyarakat, dan bernegara dan membantu mereka untuk membuat keputusan yang dapat dipertanggungjawabkan (Baidarus, 2018).

Kebiasaan yang secara sadar dilakukan secara berulang dapat membentuk karakter (Juwita et al., 2020). Ilmu sosiologi berguna dalam segala aspek kehidupan. Setiap elemen masyarakat sebagai makhluk sosial harus memahami nilai dan norma yang ada agar bisa diterima sebagai anggota masyarakat. Di dalam Sosiologi Pendidikan mengacu pada penerapan pengetahuan sosiologi, teknik berfikir, dan pengumpulan data dalam penyelidikan pendidikan. Dengan demikian sosiologi pendidikan mempelajari tentang proses pendidikan sebagai interaksi sosial, sekolah sebagai kelompok sosial, serta sebagai lembaga sosial (Daimah \& Pambudi, 2018). Salah satu tokoh dalam sosiologi yang sangat terkenal dengan teori struktural fungsional yaitu Talcott Parsons. Tujuan kajian-kajian struktural-fungsionalisme 
adalah untuk membangun suatu sistem sosial, atau struktur sosial, melalui pengajian terhadap pola hubungan yang berfungsi antara individu-individu, antara kelompokkelompok, atau antara institusi-institusi sosial di dalam suatu masyarakat, pada suatu kurun masa tertentu (Marzali, 2014).

Muara dari pendidikan karakter pada dasarnya adalah agar peserta didik atau individu dapat bersosialisasi dengan baik sesuai dengan norma dan nilai-nilai baik yang berlaku di masyarakat. Melalui hal ini penting untuk melakukan penelitian mengenai upaya pendidikan karakter di sekolah dasar berdasarkan teori struktral fungsional. Pendidikan karakter memungkinkan dapat ditinjau dari teori struktural dan fungsional. Karena teori strukural funsional yang dikemukakan Talcott Parsons memiliki keselarasan dengan penanaman pendidikan karakter mulai dari pengenalan sampai pada internalisasi nilainilai.

\section{METODE PENELITIAN}

Penelitian ini berfokus pada penggunaan upaya penanaman pendidikan karakter yang ditinjau dari teori struktural fungsional Talcott Parsons. Pendekatan dalam penelitian ini adalah pendekatan kualitatif deskriptif. Objek materil dalam penelitian yaitu upaya penanaman pendidikan karakter di SD Negeri Trayu dengan menggunakan objek formal pendekatan struktural fungsional Talcott Parsons. Metode pengambilan data melalui observasi, penelaahan/pengkajian literatureliteratur, baik klasik maupun modern yang ada kaitannya dengan judul tulisan ini. Analisis data yang digunakan peneliti adalah analisis upaya penanaman pendidikan karakter dilapangan berdasarkan teori struktural fungsional Talcott Parsons.

\section{HASIL DAN PEMBAHASAN Hakikat Pendidikan Karakter}

Undang-Undang Nomor 20 Tahun 2003 tentang Sistem Pendidikan Nasional, pada bab I tentang ketentuan umun Pasal I ayat (1) disebutkan bahwa: Pendidikan adalah usaha sadar daan terencana untuk mewujudkan suasana dan proses pembelajaran agar peserta didik ssecara aktif mengembangkan potensi dirinya untuk memiliki kekuatan spiritual keagamaan, pengendalian diri, kepribadian, kecerdasan, akhlak mulia, serta keterampilan yang diperlukan dirinya, masyarakat, bangsa dan Negara.

Hakikat pendidikan adalah usaha sadar yang dilakukan seseorang untuk menolong peserta didik dengan jalan membimbing dan mengembangkan potensi dan kepribadian serta kemampuan dasar peserta didik untuk menuju kedewasaan, berkepribadian luhur, berakhlak mulia dan mempunyai kecerdasaan berpikir yang tinggi melalui bimbingan dan latihan yang dilaksanakan dengan mengacu pada ajaranajaran yang tertera dalam al-Qur'an dan alSunnah (Chasanah, 2017).

Dari beberapa pendapat diatas dapat disimpulkan bahwa pendidikan yaitu usaha sadar dan tersisimatis untuk mewujudkan suasana belajar sehingga dapat mengembangkan potensi dan kepribadian peserta didik sebagai bekal kehidupan di masa mendatang bersama degan masyarakat. Pendidikan sebagai wadah untuk belajar bagi peserta didik, tidak hanya mengembangkan kecerdasan tetapi juga kepribadian dan segala potensi yang dimilikinya. Peserta didik harus mempersiapkan diri untukmenghadapi kehidupan di masa dewasa dan tumbuh di lingkungan masyarakat.

Kata Karakter kemudian disadur kedalam bahasa Indonesia, sehingga bila 
dilihat dalam Kamus Besar Bahasa Indonesia karakter diartikan dengan "tabiat, sifat-sifat kejiwaan, akhlak atau budi pekerti yang membedakan seseorang dengan yang lain (KBBI, 2021). Dalam literasi barat Karakter diartikan sebagai sifat kejiwaan, akhlak serta budi pekerti yang dimiliki seseorang yang membuatnya berbeda dibandingkan dengan orang lainnya, karakter juga dapat diartikan sebagai watak serta kepribadian. Karakter adalah kepribadian yang dapat dilihat dari titik moral maupun tolak etis karakter memiliki hubungan pada sifat-sifat yang umumnya tetap (Arif, 2020). Karakter merupakan struktur antropologis manusia, di sanalah manusia menghayati kebebasan dan menghayati keterbatasan dirinya. Dalam hal ini karakter bukan hanya sekedar tindakan saja, melainkan merupakan suatu hasil dan proses (Indrawan et al., 2020).

Pendidikan karakter adalah pendidikan yang diselenggarakan untuk membentuk agar para peserta didik memiliki kepribadian dan perilaku yang sesuai dengan karakter seperti dinyatakan dalam tujuan pendidikan. Pendidikan karakter diselenggarakan untuk mendorong meningkatnya potensi, bakat, kemampuan seseorang melalui proses yang sistematis dalam bentuk manusia yang berkarakter (Indrawan et al., 2020). Lickona yang mendefinisikan pendidikan karakter sebagai upaya yang sungguh-sungguh untuk membantu seseorang memahami, peduli dan bertindak dengan landasan nilai-nilai etis. Pendidikan karakter menerut Lickona mengandung tiga unsure pokok, yaitu mengetahui kebaikan (knowing the good), mencintai kebaikan (desiring the good), dan melakukan kebaikan (doing the good) (Indrawan et al., 2020).

Pada dasarnya Pendidikan karakter bertujuan untuk meningkatkan mutu penyelenggaraan dan hasil pendidikan yang mengarah pada pencapaian pembentukan karakter atau akhlak mulia peserta didik secara utuh, terpadu, dan seimbang, sesuai standar kompetensi lulusan. Melalui pendidikan karakter diharapkan peserta didik mampu secara mandiri meningkatkan dan menggunakan pengetahuannya, mengkaji dan menginternalisasi serta mempersonalisasi nilai-nilai karakter dan akhlak mulia sehingga terwujud dalam perilaku sehari-hari (Indrawan et al., 2020).

Menurut Lee dalam Journal of Science Education, menyatakan "Character and values are the essential driving forces that serve as general guides or points of reference for individuals to support decision making and to act responsibly about global socioscientific issue"s. Dapat diartikan karakter dan nilai adalah kekuatan pendorong yang penting yang berfungsi sebagai panduan umum atau titik acuan bagi individu untuk mendukung pengambilan keputusan dan untuk bertindak secara bertanggung jawab tentang masalah sosiosains global. (Garzia, 2018).

Terdapat lima nilai utama karakter yang menjadi prioritas Gerakan Penguatan Pendidikan Karakter di Madrasah. Lima nilai karakter tersebut merupakan satu kesatuan utuh yang tidak bisa di pisah-pisahkan, saling mempengaruhi dan saling menentukan dan ditentukan, yakni (Kementrian Pendidikan dan Kebudayaan Republik Indonesia, 2017): (a) Religius. Karakter religius merupakan cerminan ketaatan manusia terhadap Allah SWT, yang diwujudkan dalam sikap dan perilaku menjalankan syariat Islam, toleransi terhadap ummat yang beragama lain; meliputi tiga aspek, yakni relasi individu dengan Allah SWT, dengan sesama manusia dan dengan alam semesta. Wujud nilainya berupa cinta damai, toleransi, menghargai 
perbedaan agama, teguh pendirian, percaya diri, kerja sama lintas agama, antibuli dan kekerasan, persahabatan, ketulusan, tidak memaksakan kehendak, melindungi yang kecil dan tersisih; (b) Nasionalis, karakter nasionalis nampak dalam pola pikir, sikap dan perilaku setia, peduli, dan menghargai bahasa, lingkungan sosial dan fisik, kebudayaan, ekonomi dan politik bangsa Indonesia diatas kepentingan pribadi dan golongan. Wujud nilai karakter nasionalis berupa kesediaan menghargai dan menjaga budaya bangsa sendiri, berkorban secara ikhlas, punya prestasi, cinta tanah air, melestarikan lingkungan fisik dan sosial, mentaati aturan hukum yang berlaku, disiplin dan berdedikasi tinggi, menghargai keanekaragaman budaya, suku dan agama; (c) Mandiri, karakter mandiri nampak pada pola pikir, sikap dan perilaku yang tidak bergantung pada orang lain, serta mengoptimalkan semua tenaga, pikiran, waktu, biaya untuk mewujudkan keinginan dan cita-cita. Wujud nilai kemandirian berupa semangat kerja keras, tangguh, memiliki daya berjuang tinggi, professional, kreatif, pemberani, serta bersedia meluangkan waktu sebagai pembelajar sepanjang masa, (d) Gotong royong, karakter gotong royong nampak pada pola pikir, sikap dan perilaku kerjasama dan bahu membahu dalam menyelesaikan persoalan bersama, memperlihatkan rasa senang berbicara, bergaul, bersahabat dengan orang lain dan memberi bantuan pada mereka yang miskin, tersingkir dan membutuhkan pertolongan. Wujud nilai gotong royong berupa kesediaan saling menghargai, bekerjasama, taat keputusan, musyawarah mufakat, saling menolong, memiliki solidaritas tinggi, berempati, tidak suka diskriminasi dan kekerasan, serta rela berkorban.

Integritas, karakter integritas menjadi nilai utama yang melandasi pola pikir, sikap dan perilaku amanah, setia pada nilai-nilai sosial dan moral. Karakter integritas meliputi sikap tanggungjawab sebagai warga negara, aktif terlibat dalam kehidupan sosial, melalui konsistensi tindakan dan perkataan yang berdasarkan kebenaran. Wujud nilai integritas berupa kejujuran, cinta pada kebenaran dan keadilan, memiliki komitmen moral, tidak korupsi, bertanggungjawab, menjadi teladan, menghargai martabat individu (terutama penyandang disabilitas).

\section{Biografi Talcott Parsons}

Talcott Parsons, lahir pada 1902 di Colorado Springs, Parson berasal dari keluarga yang memiliki latar belakang yang saleh dan Intelektual, Ayahnya seorang pendeta gereja, seorang professor, dan memiliki jabatan yang tinggi di sebuah kampus kecil Parson mendapat gelar sarjana dari Amhers College tahun 1924 dan melanjutkan kuliah pascasarjana di London School of Economics, di tahun berikutnya, dia pindah ke Heidelberg, Jerman (Ritzer dkk., 1991 (Bakri, 2020)).

Persons menjadi pengajar di Harvard pada tahun 1927, dan meskipun Parsons berpindah jurusan beberapa kali, Parsons tetap berada di Harvard sampai ia wafat tahun 1979. Parsons menjadi ketua jurusan sosiologi di Harvard pada tahun 1944 dan dua tahun kemudian menduduki jabatan sebagai ketua jurusan hubungan sosial yang baru saja didirikan yang tidak hanya mempelajari ilmu sosial namun juga berbagai ilmuan sosial lain, pada tahun 1949 dipilih debagai Presiden Asosiasi Sosiologi Amerika, tahun 1950 dan 1960, dan terbitnya buku seperti The Social System (Parson, 1991(Bakri, 2020)).

Pada akhir tahun 1960, Persons diserang oleh sayap radikal sosiologi Amerika, Persons dipandang berhaluan 
politik konservstif. Holton dan Turner mungkin teoretisi yang melangkah paling jauh, dengan berargumen bahwa "karyakarya Persons, merepresentasikan kontribusi yang jauh lebih besar bagi teori sosiologi ketimbang Marx, Weber, Durkheim atau para pengikut sezamannya" terlebih lagi, gagasangagasan Persons tidak hanya memengaruhi para pemikir konservatif namun juga teoretisi neo-Marxian, khususnys Jurgen Habermas (Ritzer, 2012 (Bakri, 2020)). Talcott Parsons telah disebut sebagai orang Amerika yang paling berpengaruh sosiolog untuk karya teoretisnya tentang sistem sosial dan untuk peran pentingnya dalam menggambarkan bidang sosiologi sebagai disiplin yang berbeda (Gerhardt, 2002).

Dalam perkembangan pemikirannya ada tiga hal besar yang memengaruhi pendekatan sosiologis Parsons. Hal pertama adalah perhatian Parsons terhadap masalah kemanusiaan dalam lingkungan sosial masyarakat barat. Hal kedua adalah ketertarikan Parsons pada ilmu kedokteran. Ketertarikannya pada dunia kedokteran yang membuatnya mempelajari biologi dan filosofi, walaupun akhirnya dipisahkan oleh dunia sosiologi, tetap bertahan dan memengaruhi beberapa aspek dari ide-idenya tentang sosiologi. Hal ketiga yang memengaruhi pemikiran Parsons adalah sifat-sifat ekonomi sebagai kajian ilmiah (Turama, 2018).

\section{Teori Struktural Fungsional Talcot Parsons}

Gagasan utama Talcott Parsons dikenal sebagai teori fungsionalisme struktural. Pendekatan ini melihat masyarakat sebagai sistem yang terintegrasi secara fungsional dalam bentuk keseimbangan. Pendekatan fungsionalisme struktural ini berasal dari perspektif yang menyamakan masyarakat dengan organisme biologis. Pandangan ini merupakan pengaruh dari pandangan Herbert Spencer dan Auguste Comte yang menyatakan bahwa ada saling ketergantungan antara suatu organ tubuh dengan organ tubuh kita yang lain, dan ini dianggap sebagai kondisi yang sama dengan perusahaan

$\begin{array}{ccr}\text { Talcott } & \text { Parsons selanjutnya } \\ \text { mengembangkan } & \text { pemikirannya sebagai }\end{array}$
bahwa masyarakat harus dilihat sebagai sistem bagian-bagian yang saling bergantung. Jadi hubungan pengaruh yang mempengaruhi sampai antar bagian adalah timbal balik. Sekalipun integrasi sosial tidak pernah dapat dicapai secara sempurna, sistem sosial pada dasarnya selalu cenderung menuju keseimbangan dinamis. Meskipun ada ketegangan, disfungsi dan penyalahgunaan, sistem sosial masih dalam perjalanan menuju integrasi. Perubahan sistem sosial terjadi secara bertahap melalui adaptasi dan tidak terjadi secara revolusioner. Faktor terpenting yang memiliki integrasi suatu sistem sosial adalah kesepatakan dalam anggota masyarakat tersebut (Henderson, 2014).

Parsons juga mengembangkan konsep imperatif fungsional untuk membuat sistem bertahan. Imperatif ini biasanya disebut sebagai AGIL, yang merupakan singkatan dari Adaptation, Goal attainment, Integration, dan Latency. a.) Adaptation Ini adalah kemampuan masyarakat untuk berinteraksi dengan lingkungan yang ada dan lingkungan alam. b.) Goal Attainment Imperatif kedua ini adalah kemampuan untuk menentukan dan menetapkan tujuan masa depan dan mengambil keputusan sesuai dengan tujuan tersebut. Memecahkan masalah politik dan tujuan sosial adalah bagian dari kebutuhan ini. c.) Integration adalah keselarasan seluruh anggota sistem sosial setelah dicapai kesepakatan bersama tentang nilai-nilai atau norma-norma masyarakat. Inilah peran nilai- 
nilai tersebut sebagai integrator suatu sistem sosial. d.) Latency adalah pemeliharaan model, dalam hal ini nilai-nilai sosial tertentu seperti budaya dan bahasa (Turama, 2018).

Upaya Penanaman Pendidikan Karakter Berdasarkan Teori Struktural Fungsional

Dalam proses analisis ini peneliti menggunakan teori analisis Talcott Parsons struktural fungsional. Teori konsep imperatif fungsional untuk membuat sistem bertahan atau yang disebut AGIL (Adaptation, Goal attainment, Integration, dan Latency) sebagai strategi penerapan pendidikan karakter di sekolah dasar.

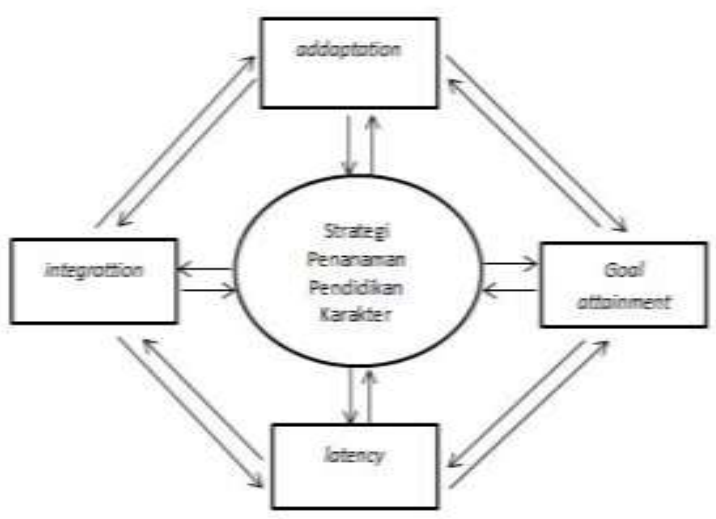

Gambar 1. Teori konsep imperatif fungsional Talcott Parsons

Pertama Adaptation, yaitu proses adaptasi nilai-nilai karakter. Sekolah menjadi tempat beradaptasi dalam menanamkan nilainilai karakter terhadap anak. Sekolah sebagai suatu sistem pendidikan memiliki serangkaian aturan dan tata tertib yang harus dipatuhi oleh peserta didik. Sebagai ekosistem belajar sekolah menjadi tempat beradaptasi dalam mengembangkan nilainilai karakter. Peserta didik akan beradaptasi mengikuti aturan dan nilai-nilai yang harus diterapkan di sekolah. Berdasarkan hasil observasi diketahui untuk meningkatkan karakter religius siswa harus beradaptasi mengikuti kegiatan tadarus dan shalat dhuha disekolah. Untuk meingkatkan karakter bertanggung jawab, siswa diharuskan beradaptasi melaksanakan tugas piket kelas di sekolah. Sekolah juga tetap berusaha menjaga nilai-nilai kesantunan atau unggahungguh dalam bahasa jawa. Siswa dibiasakan untuk berkomunikasi menggunakan bahasa Indonesia atau bahasa jawa kromo.

Hal ini juga dicontohkan Bapak/Ibu guru dalam berkomunikasi baik dengan siswa, sesama rekan guru, ataupun wali murid. Apabila melintas didepan Bapak/Ibu guru atau orang yang lebih tua siswa dibiasakan untuk menunduk, sebagai wujud rasa hormat terhadap orang yang lebih tua. Upaya upaya tersebut selaras dengan teori adaptation dalam teori Talcott Parsons yaitu agar masyarakat atau dalam hal ini peserta didik dapat bertahan maka mereka harus mampu menyesuaikan diri dengan sitem/lingkungan (Prasetya et al., 2021).

Kedua Goal Attainment, yaitu tujuan penanaman pendidikan karakter. Tujuan pendidikan karakter penting agar dalam pengambilan keputusan sesuai dengan tujuan (Turama, 2018). Pada tahap ini juga dapat disebut sebagai tahap awal penanaman pendidikan karakter. Di dalam tahap ini satuan pendidikan dapat menetapkan tujuan pendidikan karakter. Kemudian tujuan dapat diturunkan di dalam visi misi sekolah atau menjadi sebuah program dalam implementasi pendidikan karaker. Sehingga tujuan dapat terwujud dengan perencanaan dan perhitungan yang tepat. Terwujud dalam visi misi SD Negeri Trayu yaitu Visi: "Terwujudnya sumber daya manusia yang bertaqwa, berkualitas, terampil san berbudi pekerti luhur serta cinta tanah air".

Indikator berdasarkan visi tersebut diantaranya yaitu; a) unggul dalam bidang keimanan dan ketaqwaan terhadap Tuhan Yang Maha Esa, b) Unggul dalam bidang akademik yang dicapai melalui ketekunan dan kejujuran, c) unggul dalam keterampilan, 
kesenian, budaya dan kerajinan serta menguasai teknologi untuk mampu hidup mandiri, d) unggul dalam berbangsa, bernegara, dan cinta tanah air. Berdasarkan visi tersebut kemudian diturunkan misi sekolah guna mencapai visi sekolah, diantaranya; a) meningkatkan ketaqwaan terhadap Tuhan Yang Maha Esa, b) Meningkatkan pelayanan kegiatan belajar mengajar secara efektif dan optimal, c) melatih keterampilan peserta didik, d) membina peserta didik agar berbudi pekerti luhur sesuai dengan budaya Indonesia, e) menciptakan lingkungan sehat dan aman, f) membina peserta didik agar selalu cinta Bangsa dan Tanah Air Indonesia. Visi misi sekolah tersebut menjadi acuan dalam menyusun aturan dalam mengembangkan pendidikan karakter di sekolah.

Ketiga Integration, yaitu keselarasan seluruh sistem sosial. Pada tahap ini penanaman pendidikan karakter dapat diintegrasikan dengan berbagai kegiatan di sekolah baik intrakurikuler, kokurikuler maupun ekstrakurikuler. Penerapan pendidikan karakter dapat diintegrasikan dengan kegiatan intrakurikuler yaitu dengan mengintegrasikan dengan mata pelajaran dalam pembelajaran dikelas. Pengintegrasian dengan kokurikuler dapat melalui kegiatan di luar kelas seperti dalam kegiatan pembiasaan.

Pengintegrasian dengan ekstrakurikuler dapat melallui kegiatan-kegiatan pengembangan minat dan bakat peserta didik. Tahap integration ini sebagai katalisator yang mempercepat upaya penanaman pendidikan karakter. Berdasarkan hasil pengamatan seluruh anggota sistem di SD Negeri Trayu telah saling terintegrasi dalam penanaman pendidikan karakter. Pengintegrasian pendidikan karaker dalam pembelajaran di kelas telah ditunjukkan dalam deskripsi kegiatan pembelajaran dalam di dalam RPP. Guru juga telah menciptakan suasana belajar yang mendukung nilai-nilai pendidikan karakter seperti saling menghargai, mandiri, jujur, gotong royong, peduli, dan lain-lain. Bagitu pula dalam kegiatan diluar kelas seperti kegiatan kegiatan kunjungan ke perpustakaan daerah siswa juga tetap dalam pengawasan dan pemantauan guru. Dibutuhkan harmonisasi keseluruhan anggota sistem sosial setelah sebuah general agreement mengenai nilainilai atau norma-norma menjadi tata tertib sekolah telah ditetapkan. Di sinilah peran nilai tersebut sebagai pengintegrasi sebuah sistem sosial (Turama, 2018).

Keempat Latency yaitu pemeliharaan model penerapan pendidikan karakter. Tahap ini sangat penting agar penanaman pendidikan karakter dilaksanakan secara terus menerus berkesinambungan sehingga pendidikan karakter menjadi budaya yang melekat pada peserta didik. Strategi implementasi pendidikan karakter harus berkelanjutan, memadukan peran aktif siswa dan aktivitas kelas, serta dinamika seluruh sekolah yang didukung oleh pengembangan budaya sekolah yang membantu pelaksanaan penanaman pendidikan karakter. Kegiatan kegiatan yang mendukung penanman pendidikan karakter yang telah terlaksana dengan baik terus dipertahankan bahkan dikembangkan, seperti tradisi berkurban, khataman qur'an bagi siswa kelas VI, dan lain-lain. Begitu pula pada kegiatan kegiatan pembiasaan harian terus dilaksanakan dari tahun ke tahun. Upaya ini selaras dengan tujuan latency yaitu sebagai pemeliharaan pola, dalam hal ini nilai-nilai kemasyarakatan tertentu seperti budaya, bahasa, norma, aturan, dan sebagainya (Turama, 2018).

Pada tahap ini adalah upaya internalisasi nilai-nilai karakter peserta didik 
melalui penerapan dalam kehidupan seharihari baik di rumah maupun di lingkungan masyarakat. Maka peran berbagai pihak sangat berpengaruh dalam tahap ini. Orang tua sebagai orang yang bertanggung jawab terhadap anak dirumah harus turut mendukung proses internalisasi nilai-nilai karakter. Begitu pula masyarakat sebagai tempat bersosialisasi peserta didik dalam kehidupan sehari hari harus mampu menyediakan iklim yang mendukung proses internalisasi nilai-nilai luhur.

\section{KESIMPULAN}

Dari hasil penelitian ini disimpulkan bahwa penanaman pendidikan karakter di sekolah dalam hal ini dianalisis dengan pendekatan teori struktural fungsional Talcott Parsons melalui 4 tahap yaitu; penetapan tujuan penanaman pendidikan karakter goal attaintment, kemudian tahap adaptation sebagai proses adaptasi peserta didik dengan tata tertib dan kebiasaan di sekolah dalam rangka mencapai tujuan pendidikan karakter. Selanjutnya pada tahap integration penanaman pendidikan karakter dapat diintegrasikan dengan kegiatan intrakurikuler, ko kurikuler, dan ekstrakurikuler. Kemudian pada tahap latency strategi penanaman pendidikan karakter harus dilaksanakan secara terus menerus berkesinambungan sehingga menjadi budaya bagi pserta didik. Semua tahap pada konsep imperatif fungsional ini saling berpengaruh dan berkesinambungan. Sehingga ketika ada struktur atau tahap yang tidak berfungsi maka proses penanaman pendidikan karakter tidak akan berjalan maksimal.

\section{DAFTAR RUJUKAN}

Anshori, I. (2017). Penguatan Pendidikan Karakter di Madrasah. Halaqa: Islamic Education Journal, 1(2), 63-74. https://doi.org/10.21070/halaqa.v1i2.12 43

Arif, K. M. (2020). Hakikat Karakter Dan Urgensinya Dalam Perspektif Islam. Tahdzib Al-Akhlaq: Jurnal Pendidikan Islam, 3(1), 1-19. https://doi.org/10.34005/tahdzib.v3i1.82 8

Baidarus. (2018). Muhammadiyah Dan Pendidikan Karakter di Indonesia. Jurnal ISLAMIKA, 1(2), 25-44.

Bakri, W. (2020). Biografi Tokoh-Tokoh Sosiologi Klasik sampai Postmodern. https://doi.org/10.31219/osf.io/5kt8z

Chasanah, U. (2017). Ontologi, epistemologi dan aksiologi pendidikan. tasyri' Jurnal Tarbiyah syari'ah islamiyah, 24(1), 7691.

Daimah, D., \& Pambudi, S. (2018). Pendekatan Sosiologi Dalam Kajian Pendidikan Islam. Jurnal Pendidikan Islam, $\quad 9(2), \quad 115-126$. https://doi.org/10.22236/jpi.v9i2.1814

Garzia, M. (2018). Urgensi pendidikan karakter abad 21 pada anak usia dini. Urgensi Pendidikan Karakter Abad 21 Pada Anak Usia Dini, 357-361.

Gerhardt, U. (2002). Talcott Parsons: an intellectual biography. In Cambridge University Press (Vol. 1). https://doi.org/10.5860/choice.40-6728

Henderson, L. J. (2014). Iv. the Social System. In Pareto's General Sociology. https://doi.org/10.4159/harvard.9780674 493155.c3

Indrawan, I., Wijoyo, H., Suherman, \& Wiguna, i made arsa. (2020). Manajemen Pendidikan Karakter. In Paper Knowledge. Toward a Media History of Documents.

Juwita, R., Firman, F., Rusdinal, R., Aliman, M., \& Malang, U. N. (2020). Meta Analisis: Perkembangan Teori Struktural Fungsional dalam Sosiologi Pendidikan. 3(1), 1-8.

KBBI, D. (2021). Karakter. KBBI Daring. https://kbbi.kemdikbud.go.id/entri/KAR AKTER

Kementrian Pendidikan dan Kebudayaan Republik Indonesia. (2017). Konsep 
Dan Pedoman Penguatan Pendidikan Karakter Tingkat Sekolah Dasar dan Sekolah Menengah Pertama (Vol. 1). https://doi.org/10.1016/j.smr.2019.08.00 5\%0Ahttp://dx.doi.org/10.1016/j.smr.20 09.02.001\%0Ahttps://scholarship.shu.ed u/student_scholarship

Marzali, A. (2014). StrukturalFungsionalisme. Antropologi Indonesia, $0(52)$.

https://doi.org/10.7454/ai.v0i52.3314

Prasetya, A., Nurdin, M. F., \& Gunawan, W. (2021). Perubahan Sosial Masyarakat dalam Perspektif Sosiologi Talcott Parsons di Era New Normal. Sosietas
Jurnal Pendidikan Sosiologi, 11(1), 929-939.

Rohendi, E. (2010). Pendidikan Karakter Di Sekolah. International Institute for Environment and Development, 07/80(2), 125. https://ejournal.upi.edu/index.php/eduhu maniora/article/view/2795/1824

Sidi, P. (2014). Krisis Karakter The Crisis Of Characters. 2, 72-81.

Turama, A. R. (2018). Formulasi Teori Fungsionalisme Struktural Talcott Parsons. jurnal Univeristas Sriwijaya, 58-69. 